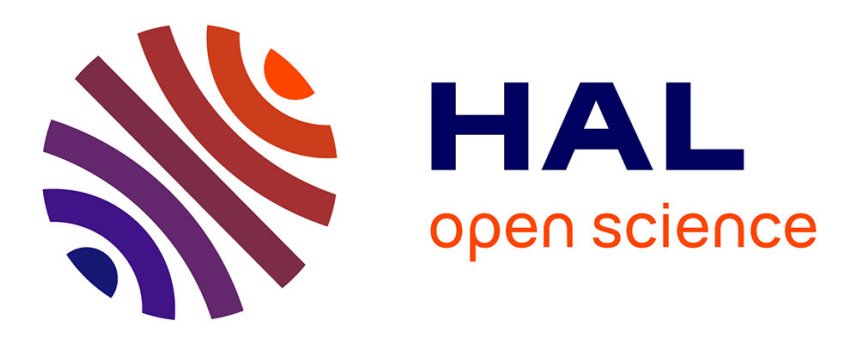

\title{
Use of magnetic fields in electrochemistry: a selected review
}

\author{
Vivien Gatard, Jonathan Deseure, Marian Chatenet
}

\section{To cite this version:}

Vivien Gatard, Jonathan Deseure, Marian Chatenet. Use of magnetic fields in electrochemistry: a selected review. Current Opinion in Electrochemistry, 2020, 23, pp.96-105. 10.1016/j.coelec.2020.04.012 . hal-02953311

\section{HAL Id: hal-02953311 \\ https://hal.univ-grenoble-alpes.fr/hal-02953311}

Submitted on 30 Sep 2020

HAL is a multi-disciplinary open access archive for the deposit and dissemination of scientific research documents, whether they are published or not. The documents may come from teaching and research institutions in France or abroad, or from public or private research centers.
L'archive ouverte pluridisciplinaire HAL, est destinée au dépôt et à la diffusion de documents scientifiques de niveau recherche, publiés ou non, émanant des établissements d'enseignement et de recherche français ou étrangers, des laboratoires publics ou privés. 


\section{Use of magnetic fields in electrochemistry: a selected review.}

$$
\text { Vivien Gatard }{ }^{1-2}+\text {, Jonathan Deseure }{ }^{1} \text {, Marian Chatenet }{ }^{1}+
$$

\footnotetext{
${ }^{1}$ Univ. Grenoble Alpes, Univ. Savoie Mont Blanc, CNRS, Grenoble INP (institute of engineering, Univ. Grenoble Alpes), LEPMI, 38000 Grenoble, France

${ }^{2}$ Laboratoire de Physique et Chimie des Nano Objets, INSA, Université de Toulouse, 135, Avenue de Rangueil, F-31077 Toulouse, France
}

+Corresponding author:

Tel.: +33 4768266 54; E-mail address: vivien.gatard@ grenoble-inp.fr

Tel.: +334 768265 88; E-mail address: marian.chatenet@ grenoble-inp.fr 


\begin{abstract}
:
Electrochemical reactions are usually thermally-activated and submitted to masstransfer effects. Although classically, enhanced kinetics of an electrochemical reaction is obtained by heating the cell and feeding the reactant by forced convection, other means can be used to improve mass- and charge-transfer. This paper shortly reviews the effects of magnetic fields in electrochemistry. Using a static or an alternating magnetic field enables to enhance electrodeposition and electrocatalysis, via improved gas and species convection, electrochemical kinetics and whole reaction efficiency. Such enhancement can mainly be related to Lorentz and Kelvin forces, magneto-hydrodynamics (MHD), chiral-induced spin selectivity (CISS) and hyperthermia, these effects being described herein.
\end{abstract}

Keyword: magnetic field; Lorentz force; Kelvin force; electrodeposition; charge-transfer; spindependent electrochemistry; electrocatalysis 


\section{Highlights:}

- The Lorentz force induces convection (via MHD and micro-MHD effects).

- The Kelvin force induces convection in magnetic field gradient on para(dia)magnetic species.

- The polarization of the spins influences reaction pathways.

- Hyperthermia, a local heating of the electrode materials, enhances reaction kinetics. 


\section{Introduction}

Electrochemical reactions are usually thermally-activated and submitted to masstransfer effects. Although classically, enhanced kinetics of an electrochemical reaction is obtained by heating the cell and feeding the reactant by forced convection, other means can be used to improve mass- and charge-transfer. Although not trivial and beyond the usual electrochemists' expertise, magnetic fields are coupled with electrochemistry since 40 years. Researchers firstly observed its effect on mass-transfer, limiting current density and chargetransfer [1][2][3][4], and electrodeposition [5]. Many practically-interesting results were obtained in various domains, e.g. proton exchange membrane fuel cells (PEMFC) [6][7], electrodeposition [8], lab-on-chips [9] or enantioselectivity [10]. Whether the magnetic field is alternating (AMF) or static (SMF), and applied parallel $\left(B_{/ /}\right)$or perpendicular $(B \perp)$ to the electrode surface, several effects (forces) can be triggered, such as Lorentz and Kelvin forces $[11,12]$. Generally, these phenomena are concomitant, and isolating their individual influence is difficult; this selected-review aims to summarize and discuss the main results obtained recently on the theme.

\section{Static Magnetic Field}

\subsection{The Lorentz force}

The most common and earliest-studied effect [1] upon application of a SMF in electrochemistry is the Lorentz force density $\boldsymbol{F}_{\mathrm{L}}{ }^{1}$ (equation 1):

$$
\boldsymbol{F}_{\mathrm{L}}=\boldsymbol{J} \times \boldsymbol{B}
$$

where the current density of electrochemical process is (equation 2):

\footnotetext{
${ }^{1}$ In this review, vectors are written in bold fonts $(e . g$. vector $\boldsymbol{B})$ and their modulus are in normal fonts $(\|\boldsymbol{B}\|=B)$.
} 


$$
\boldsymbol{J}=\sigma(\boldsymbol{E}+\boldsymbol{v} \times \boldsymbol{B})-n \mathcal{F} D_{+,-} \nabla c_{+,-}
$$

with $\boldsymbol{E}$ the electric field, $\sigma$ the electrical conductivity, $\boldsymbol{v}$ the velocity of charged species and $\boldsymbol{B}$ the magnetic field. $\sigma(\boldsymbol{v} \times \boldsymbol{B})$ is the induced current, $n$ the charge number of the electroactive ionic species $c_{+,-}, D_{+,-}$its diffusion coefficient and $\mathcal{F}$ the Faraday constant. The diffusion of ions in the electrolyte during electrolysis increases the concentration gradient, implying higher reaction overvoltage [13]. Expressing the diffusion current density in MHD investigation is uncommon [14], but considering this effect is nevertheless relevant. Under AMF exposure or with a gas-evolving electrode, non-static effects could involve diffusion current, which depend on local potential variations, the value of which are difficult to access. ${ }^{2}$ The Lorentz force acts on moving charged species, depends on their velocity and the magnetic field amplitude; it is maximal (resp. minimal) when $\boldsymbol{v}$ and $\boldsymbol{B}$ are orthogonal (resp. parallel). Its order of magnitude $\sim 10^{3} \mathrm{~N} / \mathrm{m}^{3}$ for $B=1 \mathrm{~T}$ and for $J=100 \mathrm{~mA} / \mathrm{cm}^{2}$, is comparable to the buoyancy force [15] but remains inferior to mechanical-stirring. Its common effect is to thin the diffusion layer, which improves mass-transfer to the electrode [16][17][18]. In electrodeposition, the deposition rate and limiting current density are increased proportionally to $B^{1 / 3}[19][20][21]$. The effect of the field-magnitude strongly depends on the distance $d$ from the permanent magnet, decreasing as $1 / d^{2}$, as studied by Mogi et al. for a $B \perp[22]$.

Lorentz force can induce flow patterns at a very small scale, where high current density can exist, which is impossible via mechanical-agitation. At the edge of an electrode with a SMF perpendicular to the electrode surface, the current density is no longer parallel to the SMF, inducing magneto-hydrodynamic (MHD) effect / micro-MHD convection; this corresponds to circular vortices around nucleation sites $\left(\boldsymbol{F}_{\mathbf{L}}\right.$ along $\boldsymbol{u}_{\boldsymbol{\theta}}$ in polar coordinates), favoring two-

\footnotetext{
${ }^{2}$ A quick estimation from usual gradient values [13] reaches $10^{1}-10^{3} \mathrm{~N} / \mathrm{m}^{3}$. However, the authors have never seen this scrutinized in the literature.
} 
dimensional growth against three-dimensional growth (Figure 1a,b) [23][24]. Many related effects were observed during electrodeposition, depending on the applied magnetic field direction on the cathode surface. $B / /$ can induce smoother deposits, more homogeneous surface with finer grains and better magnetic properties (for electroplated amorphous quaternary FeNiPGd films, Figure 1c) Erreur ! Source du renvoi introuvable.[25]. Besides, crystallographic growth-directions are preferred for metallic electrodeposits, which can alter the deposits shape [26].

The rest potential for (non)magnetic electrodes can be shifted with a $B \perp$, leading to rougher deposits [27][28] or enhanced corrosion [29][30][31], these effects depending on the operating parameters. Using a rotating magnetic field or a $B \perp$, Mogi et al. selectively-deposited an enantiomer preferentially to the other, depending on the polarity of the magnetic field [22][32]. Zou et al. used a rotating $\mathrm{SMF}$ to create dendrites of self-supported $\mathrm{Ni}_{\mathrm{x}} \mathrm{Co}_{1-\mathrm{x}}$ nanowire membrane [33]. In both cases, the film thickness is generally larger, owing to enhanced masstransfer [25]. 
a

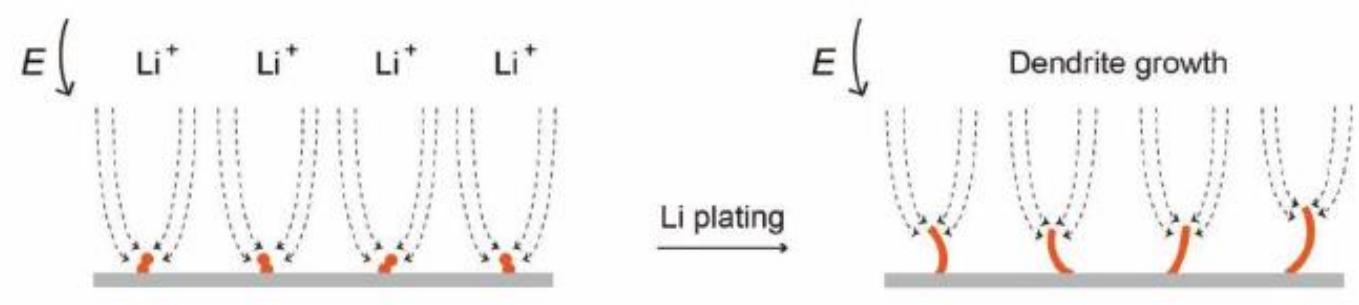

b
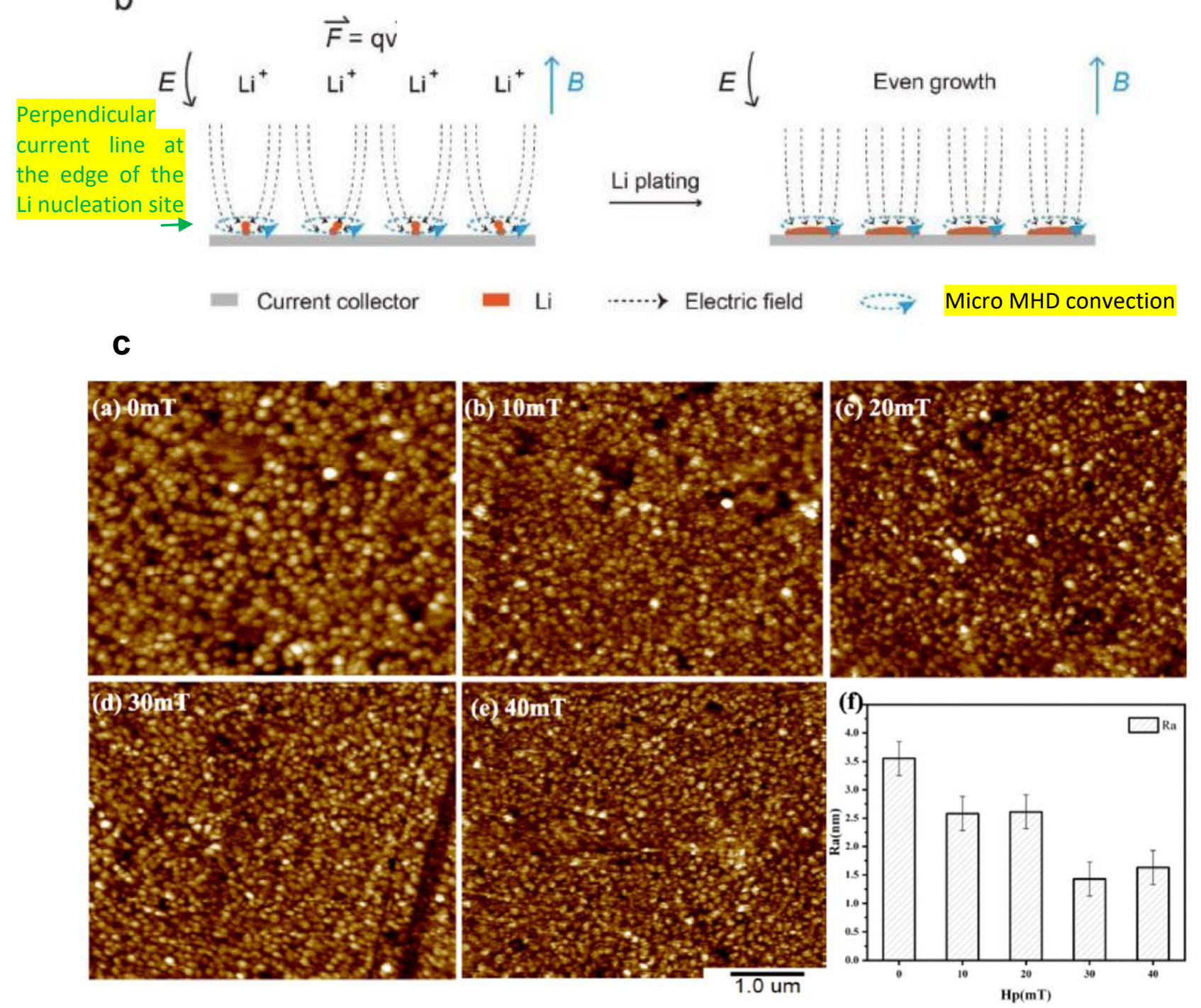

Figure 1: Using the Lorentz force in electrodeposition. a,b) To eliminate Li dendrite

growth. a) The electric field around lithium nucleii or protuberances on the current collector is larger than for flat areas, inducing $\mathrm{Li}^{+}$flow towards the tips and yielding dendrite growth. $\mathrm{b}$ ) With a magnetic field applied perpendicular to the current collector, local $\mathrm{Li}^{+}$flux around the tip area cuts perpendicularly the magnetic line, inducing Lorentz force and micro-MHD vortices (swirling convection), leading to more homogeneous Li plating. Reproduced from [23] with 
permission from Wiley. c) During plating of FeNiPGd films. Atomic force micrographs of FeNiPGd films electroplated at different magnetic fields amplitude $B=$ (a) $0 \mathrm{mT}$, (b) $10 \mathrm{mT}$, (c) $20 \mathrm{mT}$, (d) $30 \mathrm{mT}$, (e) $40 \mathrm{mT}$; and (f) roughness value $(R a)$ of the films obtained under different magnetic field intensity $(10 \mathrm{mT}<B<40 \mathrm{mT})$. Reproduced from [25] with permission from Elsevier.

SMF also influence bubbles: both $B \perp$ or $B / /$ favor bubbles removal, lured by micro-MHD convection in the clockwise or anticlockwise direction, depending on the sign of the charge adsorbed on the bubble [16]. This reduces the electrode masking by decreasing the bubbles' coverage, e.g. for water-splitting reaction, thereby reducing the Ohmic-loss and increasing the number of nucleation sites [34]. Bubbles removal also fosters better electrodeposits with fewer vacancies and defects [18][35]. Using a CCD camera for $\mathrm{H}_{2}$ generation under SMF, Liu et al. showed a bubbles' size reduction ranging from 50 to $100 \mu \mathrm{m}$ on a magnetized $\mathrm{Ni}$-wire electrode (residual magnetic field: $B_{\mathrm{r}}=0.03 \mathrm{~T}$ ) [15][17][36][37].

Better efficiency of polymerization [38], organic reactions [39] and water reduction/oxidation were also recorded [34][40], these examples further demonstrating the impact of the Lorentz force in electrochemistry.

\subsection{The Kelvin force}

"Kelvin effects are ubiquitous because any single-electron-transfer redox process generally involves paramagnetic species. Magnetic species in an electrolyte are usually paramagnetic cations, free-radicals or molecular species with unpaired spin such as $\mathrm{O}_{2}$. An applied field H induces a magnetization $M=\chi H$, where, $\chi\left(=\chi_{m} c^{3}\right)$ is the dimensionless Curie-

\footnotetext{
${ }^{3}$ Some authors propose [77] to write the susceptibility as the sum of two contributions: solvent and electrochemical reactants $\left(\chi=\chi_{\mathrm{s}}+\chi_{\mathrm{m}} c\right)$, where $\chi_{\mathrm{m}}$ is the molar susceptibility of the electroactive species $c$ and $\chi_{\mathrm{s}}$ the susceptibility of the solvent. Nevertheless, $\chi_{\mathrm{s}}$ is generally far below $\chi_{\mathrm{m}} c$.
} 
law magnetic susceptibility”, proportional to the spin of the species in aqueous solution [12]. The Kelvin force density (also denominated magnetic field-gradient force or magnetophoretic force) is given by equation 3:

$$
\boldsymbol{F}_{\mathbf{K}}=1 /\left(2 \mu_{0}\right) c \chi_{\mathrm{m}} \nabla\left(B^{2}\right)
$$

with $\mu_{0}$ the magnetic constant in free space, $c$ the concentration and $\chi_{\mathrm{m}}$ the molar magnetic susceptibility. Independent on the magnetic field direction, this force creates convection, which drives paramagnetic species $(\chi>0)$ towards high magnetic field gradient and diamagnetic species $(\chi<0)$ towards low magnetic field gradient. Order of magnitude from $10^{3}$ to $10^{6-7} \mathrm{~N} / \mathrm{m}^{3}$ can be reached at the vicinity of micrometer-size ferromagnetic (FM) element, the strength increasing for smaller FM objects [12]. Okada et al. used this effect for the ORR in a PEMFC, using a magnetized [20 wt.\% Pt/C + Nd/Fe/B nanoparticles (NPs)] electrode under a magnetic field $B=4 \mathrm{~T}: \mathrm{O}_{2(\mathrm{~g})}\left(\chi_{\mathrm{m}}=3.449 \times 10^{-6} \mathrm{~cm}^{3} / \mathrm{mol} \gg \chi_{\mathrm{m}}=-12.96 \times 10^{-6} \mathrm{~cm}^{3} / \mathrm{mol}\right.$, for liquid water at $T=273 \mathrm{~K}$ [41]) was attracted toward the cathode surface, limiting the mass-transfer issues [7]. This force being non-conservative $\left(\nabla \times F_{K}=\left(1 / 2 \mu_{0}\right) \chi_{\mathrm{m}}\left[\nabla(\boldsymbol{c}) \times \nabla\left(\boldsymbol{B}^{2}\right)\right]\right.$, convection should arise in region of non-uniform concentration if the concentration gradient is perpendicular to the magnetic field gradient, thereby thinning the diffusion layer and enhancing mass-transfer, as for the MHD effect [30]. Using field gradient near the working electrode (WE) surface with magnetic elements (3d-elements), direct and inverse patterning could be obtained upon electrodeposition [12][42][43].

\subsection{Spin-dependent electrochemistry}

Another domain of growing interest is the spin-polarization of exchanged electrons and open-shell (valence) electrons of catalysts. Naaman et al. observed that chiral compounds act as spin-filter: one polarization of the electron's spin is favoured against the other when transmitted through a chiral molecule, yielding a current of polarized-spins. This "chiral- 
induced spin-selectivity" (CISS) [44] was applied in several domains [28,45-47]; spinpolarization was observed using FM or antiferromagnetic (AFM) WE [45], and used to reach giant-magnetoresistance [48]. By polarizing the spin through a chiral compound or by applying a magnetic field on a ferromagnetic WE, enhanced electron-transmission was observed for $\mathrm{O}_{2}$ evolution, while the side reaction of $\mathrm{H}_{2} \mathrm{O}_{2}$ production was reduced during water-splitting [30][46][49][50][51]. The effect is explained by the more favourable energetic path of the transferred electrons upon polarization: when the $\mathrm{OH} \cdot$ radicals reacting into $\mathrm{O}_{2}$ have their electronic spin co-aligned in the laboratory frame, they interact on a triplet potential, yielding triplet oxygen, whereas peroxide formation is symmetry-forbidden (Pauli principle, Figure 2) [46]. One can imagine that by polarizing the electrons, the overlap-integral of the radicals' molecular orbitals is higher than without polarization, leading to the formation of more kinetically-favourable species, even though the thermodynamics is not favoured. Density Functional Theory (DFT) calculations indicated that the energy difference between the triplet and singlet state of $\mathrm{O}_{2}$ is $c a .1 \mathrm{eV}$ [9][52][53]. By simply approaching a permanent magnet (B $=450 \mathrm{mT})$ to a $\mathrm{NiZnFe}_{4} \mathrm{O}_{\mathrm{x}} / \mathrm{Ni}$-foam FM WE, Garcès-Pineda et al. enhanced the oxygen evolution reaction (OER) current from 24 to $40 \mathrm{~mA} / \mathrm{cm}^{2}$ at $1.65 \mathrm{~V}_{\mathrm{RHE}}$. Knowing that $3 \mathrm{~d}$ elements have a maximum spin-polarization of 40 and $23 \%$ for Fe and Ni respectively [45][54], and that a $450 \mathrm{mT}$ magnet is probably insufficient to reach the maximum catalyst spinpolarization, superior performances might be reached [53]. This enhanced electrontransmission was explained by a decreased energy-barrier under magnetic field, following the Zeeman effect, even if this perturbation might be very small [31][55]. Forslund et al. studied the overlap-integral between the $\mathrm{Ni}$ and $\mathrm{Fe} 3 \mathrm{~d}$ bands and the $\mathrm{O} 2 \mathrm{p}$ band for Ruddlesden-Popper oxides: cross-gap hybridization between $\mathrm{e}_{\mathrm{g}}(\mathrm{Ni}), \mathrm{p}(\mathrm{O})$ and $\mathrm{e}_{\mathrm{g}}(\mathrm{Fe})$ bands across the Fermi level were predicted (DFT calculations) to enhance both charge-transfer interactions across $\mathrm{Fe}-\mathrm{O}-$ Ni bridges and the bandwidth available for electrode-adsorbate electron transfer. The sufficient 
Fe content favoured the 4-electron pathway (yielding HO-) over the 2-electron pathway (yielding HOO· ) [56]. Spin-dependent electrochemistry (SDE) induced enantioselectivity too, as observed for oxalate oxidation [57].
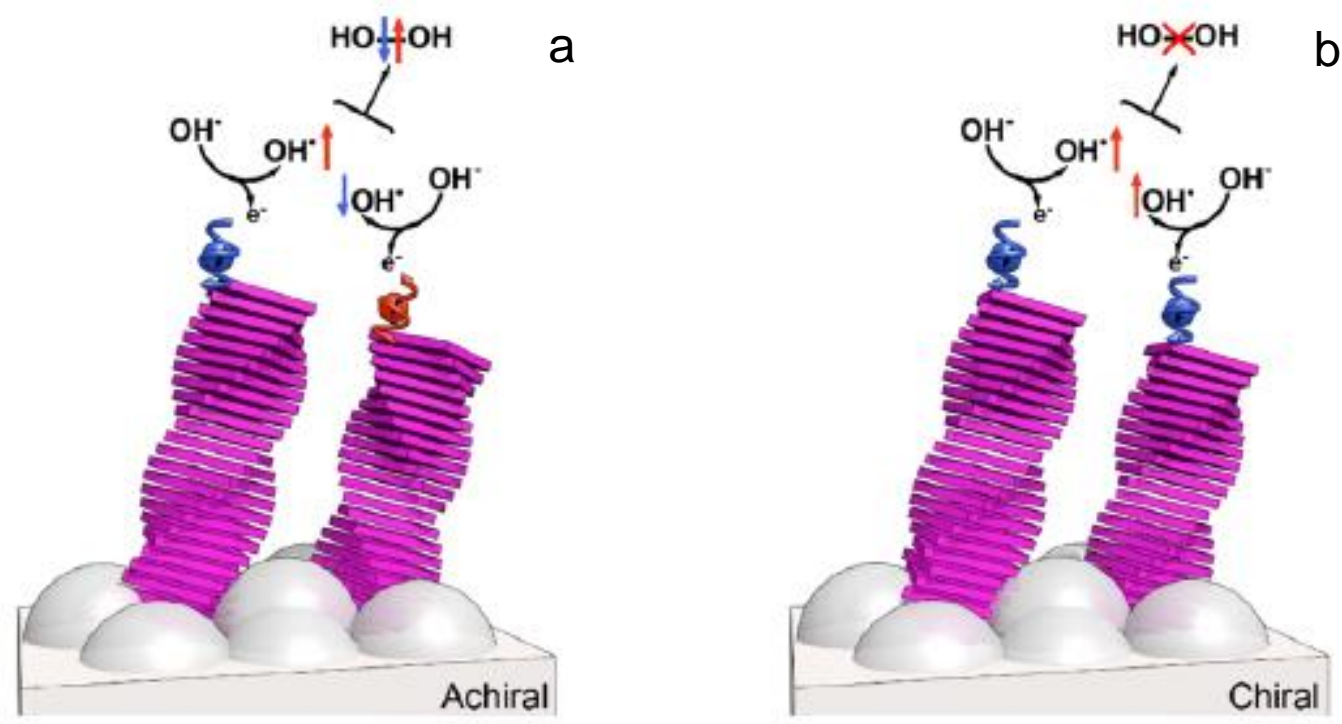

Figure 2: Spin-dependent electrochemistry. In a) the support is achiral so the spins are not polarized, allowing the interaction on the singlet potential, yielding the thermodynamicallyfavourable hydrogen peroxide. In b) the hydrogen peroxide is forbidden because the photoanode induces polarized spin that interacts on the triplet potential, favouring $\mathrm{O}_{2}$ evolution. Reproduced from [46] with permission from Wiley.

Others studied the binding of reaction intermediates on FM or AFM WE, notably for the OER and ORR. Using DFT calculations, assuming quantum spin-exchange interaction (QSEI) for 3d-elements, they showed that the binding-strength can be controlled through spinpolarization. Dominant AFM QSEI enhance the interatomic Coulomb potential and pairlocalization versus a nonmagnetic covalent structure, while dominant FM QSEI lowers electronic repulsion and reduces pair-localization. The FM intra-atomic QSEI decreases the adsorption enthalpies of reactants, yielding milder oxidant intermediates adsorption and enhanced ORR activity. On the contrary, dominant interatomic AFM pair-localization lowers 
the conductivity, leading to decreased ORR efficiency. Pair-localization and strong couplings in fully AFM-orderings may strongly decrease some reaction intermediates chemisorption, detrimentally-affecting reactivity [58][59][60][61][62]. According to Barut and Kraus [63], magnetic interactions play the dominant role at small distances, likely inducing additional effects than the Coulomb interaction of $\mathrm{e}^{+} \mathrm{e}^{-}$system (two-body bound state), e.g. symmetry of the potential, leading to such local energy modification.

Although spin-polarization is thrilling, it faces limitations: it is constrained by the lifetime and distance over which the electrons' spin is conserved. Bullard et al. used magneticconducting atomic-force microscopy to show that the polarized current created by the CISS effect can flow through achiral molecules over $\approx 35 \AA$, which exceeds the length of chiral moiety ( $\approx 15 \AA$ ) [64], while Mishra et al. observed CISS effects through extracellular conduits, over distances above $10 \mathrm{~nm}$ [65]. Kumar et al. recorded a long-lifetime (> $10 \mathrm{~ms}$ ) in an AlGaN/GaN device [66]. Furthermore, the spin-selectivity may be $\mathrm{pH}$-dependent for certain reactions, as Garcès-Pineda et al. did not observe spin-restriction for water splitting at pH 11 using Ni-foam-supported 3d-element oxides in $1 \mathrm{M} \mathrm{KOH}$ electrolyte [53], while Tassinari et $a l$. observed enhanced HER with $\mathrm{TiO}_{2}$ NPs coated with a chiral poly(fluorene-co-thiophene) and decorated with CdSe quantum dots in $0.35 \mathrm{M} \mathrm{Na}_{2} \mathrm{SO}_{3}+0.25 \mathrm{M} \mathrm{Na}_{2} \mathrm{~S}$ aqueous electrolyte solutions ( $\mathrm{pH}$ 9.5) [67]. These results indicate that the rate-limiting step is not spin-restricted under different $\mathrm{pH}$ conditions, or with different catalysts.

\section{Alternating magnetic field (AMF)}

To our knowledge, only one work reported the effect of an AMF on water electrolysis processes [68]: Niether et al. used carbon-felt-supported core-shell magnetic and catalytic NPs as electrode in AMF-enhanced alkaline water-splitting. Under radiofrequency (300 kHz) AMF, 
the NPs magnetization changes direction with the AMF direction, the induced work releasing heat, which heightens the NPs temperature. This principle, hyperthermia, was first used for cancer therapy [69]. The heating of the NPs, characterized by the Specific Absorption Rate (SAR) value (the area $A$ of the hysteresis-loop multiplied by the frequency $f$, equation 4) [70], enhances the reaction kinetics (Figure 3).

$$
\mathrm{SAR}=\int_{-H \max }^{+H \max } \mu_{0} M(H) \mathrm{d} H f
$$

OER and HER chronopotentiometric measurements showed decreased overpotential by 250 and $150 \mathrm{mV}$, respectively, for $B=48 \mathrm{mT}, J=18 \mathrm{~mA} / \mathrm{cm}^{2}$, although heating may not be the only effect at stake (Kelvin of Lorentz forces may help releasing $\mathrm{O}_{2}$ gases).

Other works used switchable magnetic field to micro-manipulate single $\mathrm{Fe}_{3} \mathrm{O}_{4}$ microparticles, and take benefit of their electrochemical activity by attracting or removing the particles by switching on or off a magnetic field [71]. Manipulating particles individually may be of interest for several domains such as engineering, biology, chemistry and physics.

Besides, AMF has been used to magnetized sea water $(0.3 \mathrm{~T}$ at $25 \mathrm{~Hz})$, which then shows notably limited corrosion effect on $\mathrm{Cu}$ (corrosion current reduced by 10), and fewer corrosion products [72]. 

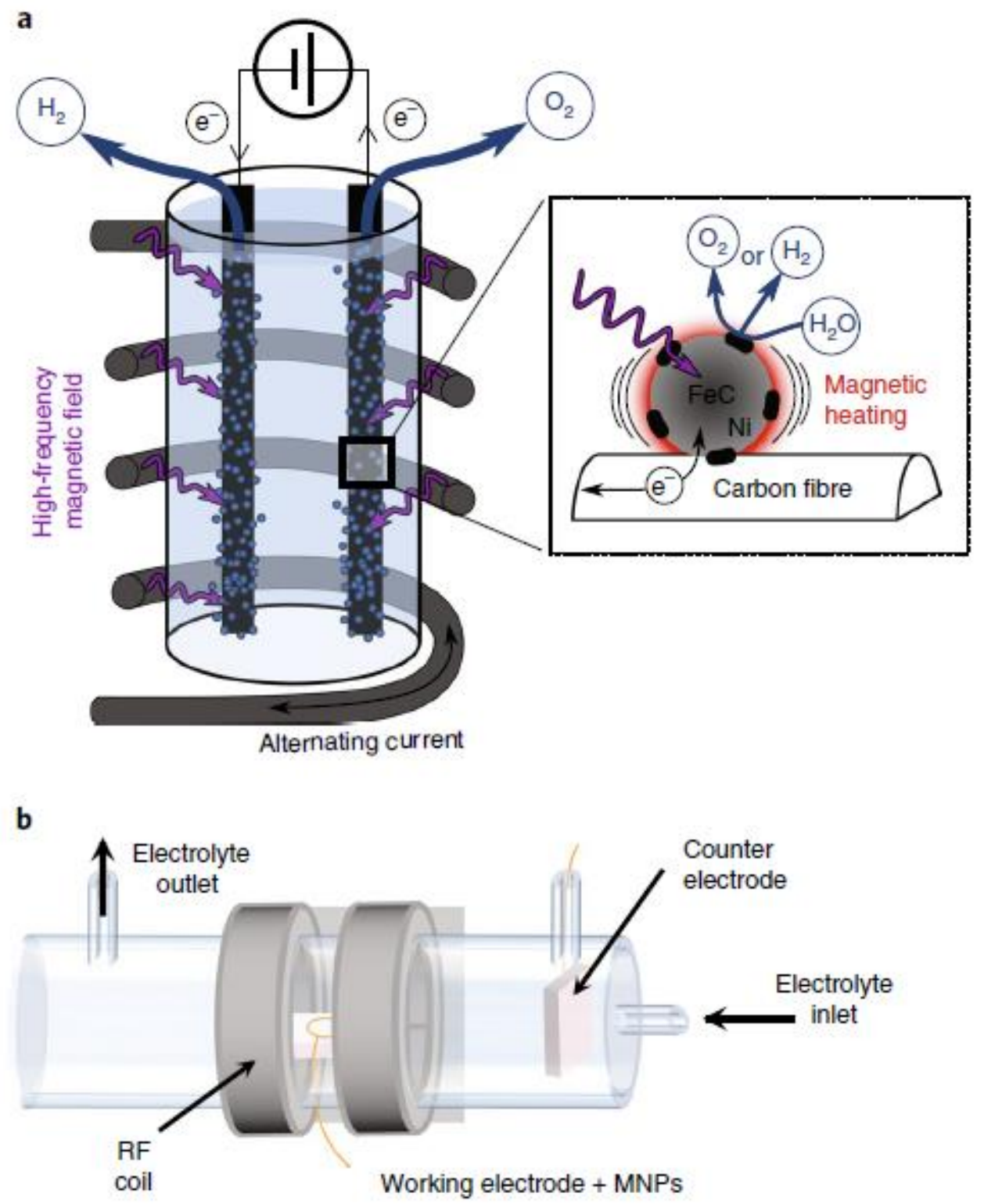

Figure 3: Water electrolysis activated by the local heating of MNPs in an AMF (Hyperthermia). a) General representation of the AWE cell operating inside the coil that generates the AMF, the cell being, ideally, powered with renewable electricity. b) Schematics of the electrolysis AWE flow-cell set-up. Reproduced from [68] with permission from SpringerNature. 


\section{Concluding remarks}

Many different puzzling effects at several length scales are observed when coupling alternating or static magnetic field with electrochemistry. The most important are the (i) Lorentz force, inducing convection (MHD and micro-MHD effects), (ii) Kelvin force, inducing convection in magnetic field-gradient on para(dia)magnetic species (iii) spin-polarization, orienting reaction pathways and (iv) hyperthermia, a local heating at the electrode surface, that enhances reaction kinetics. Although qualitative explanations are proposed, these phenomena are not fully-investigated yet and no uniform/universal model exists to explain them, though numerical calculations tried to explain MHD convection [73]. A permanent magnet of $B \approx 1 \mathrm{~T}$ or Helmholtz coils are usually used to trigger the effects, and specially-designed cells are necessary to scrutinize them, a hurdle for industrial applications. Table 1 summarizes some recorded enhancements of water oxidation/reduction reaction, thanks to the application of a magnetic field.

Other effects were reported, like liquid-metal droplet actuation induced by a magnetic field [74][75][76], that are not presented here. Neither are exposed the techniques used to measure spin-polarization [9][51], and the force acting on the double layer or the one proportional to $\boldsymbol{\nabla}(\mathrm{c}) * \boldsymbol{B}^{2}$ [8][28], although Coey et al. found it negligible [77]. Anyway, these discoveries are the "tip of the iceberg" for many applications, especially for spin-dependent electrochemistry, and they could have major impacts in several domains, notably for watersplitting at lower voltage, hence lower prices. 
Table 1: selected summary of the main "magnetic effects" mentioned for electrochemical reactions (results with currents above $c . a . \mathrm{mA} / \mathrm{cm}^{2}$ have been recorded).

\begin{tabular}{|c|c|c|c|c|c|c|}
\hline & Effect/equation advanced & $\|B\|$ applied & $\begin{array}{l}\text { Overpotential } \\
\text { and current } \\
\text { density }\end{array}$ & Catalysts & $\begin{array}{l}\text { Medium } \\
\text { (alkaline/acid) }\end{array}$ & References \\
\hline & $\begin{array}{l}\text { Spin-polarization of } \mathrm{O}_{2} \\
\text { electrons }\end{array}$ & $\begin{array}{l}\leq 450 \mathrm{mT} \\
\text { during } \\
\text { experiment }\end{array}$ & $\begin{array}{l}24 \rightarrow 40 \mathrm{~mA} / \mathrm{cm}^{2} \\
\text { at } 1.65 \mathrm{~V}_{\mathrm{RHE}}(\mathrm{iR}- \\
\text { compensated) }\end{array}$ & $\begin{array}{l}\mathrm{NiZnFe}_{4} \mathrm{O}_{x} / \mathrm{Ni}- \\
\text { foam electrode }\end{array}$ & $\begin{array}{l}\text { alkaline } \mathrm{pH} 14 \\
(1 \mathrm{M} \mathrm{KOH})\end{array}$ & {$[53]$} \\
\hline & $\begin{array}{l}\text { large surface areas } \\
\text { (incomplete Ostwald } \\
\text { ripening), fast charge/mass } \\
\text { transportation ability (metallic } \\
\text { phase) and possible lattice } \\
\text { defect-enhancement effect }\end{array}$ & $\begin{array}{l}\text { Only used to } \\
\text { create the } \\
\text { nanowires }\end{array}$ & $\begin{array}{l}-150 \mathrm{~mA} / \mathrm{cm}^{2} \text { at }- \\
0.2 \mathrm{~V}_{\mathrm{RHE}}\end{array}$ & $\begin{array}{l}\mathrm{Ni}_{0.5} \mathrm{Co}_{0.5} \\
\text { nanowire } \\
\text { membrane }\end{array}$ & $\begin{array}{l}\text { alkaline } \mathrm{pH} 14 \\
(1 \mathrm{M} \mathrm{KOH})\end{array}$ & [33] \\
\hline SMF & $\begin{array}{l}\text { Lorentz force which triggers } \\
\text { gas elimination and the } \\
\text { reduction of average gas } \\
\text { fraction at electrode surface }\end{array}$ & $0.9 \mathrm{~T}, \mathrm{~B}_{/ /}$ & $\begin{array}{l}\text { Cell voltage } 3.95 \\
\mathrm{~V} \text { at } 1.25 \mathrm{~A} / \mathrm{cm}^{2}\end{array}$ & $\begin{array}{l}\text { two Platinum } \\
\text { sheets }(4 \times 4 \\
\text { mm) are used } \\
\text { as anode and } \\
\text { cathode }\end{array}$ & $4.24 \mathrm{M} \mathrm{KOH}$ & [17] \\
\hline & $\begin{array}{l}\text { Lorentz force which drives } \\
\text { away } \mathrm{H}_{2} \text { bubbles }\end{array}$ & $0.9 \mathrm{~T}, \mathrm{~B}_{/ /}$ & $\begin{array}{l}\text { Cell voltage of } 3.3 \\
\mathrm{~V} \text { at } 200 \mathrm{~mA} / \mathrm{cm}^{2}\end{array}$ & $\begin{array}{l}\text { foam copper } \\
\text { was cut as the } \\
\text { cathode and a } \\
\text { nickel one as } \\
\text { the anode }\end{array}$ & $0.2 \mathrm{M} \mathrm{KOH}$ & {$[25]$} \\
\hline & $\begin{array}{l}\text { Lorentz force (MHD) } \\
\text { reducing hydrogen bubble }\end{array}$ & $\begin{array}{l}\text { magnetized } \\
\text { electrode }\left(\mathrm{B}_{\mathrm{r}}\right. \\
=30 \mathrm{mT})\end{array}$ & $0.4 \mathrm{~mA} / \mathrm{cm}^{2}$ & $\begin{array}{l}\text { Ni wire as } \\
\text { cathode }\end{array}$ & $\begin{array}{l}\text { alkaline } \mathrm{pH} 14 \\
(1 \mathrm{M} \mathrm{KOH})\end{array}$ & {$[37]$} \\
\hline
\end{tabular}




\begin{tabular}{|c|c|c|c|c|c|c|}
\hline & $\begin{array}{l}\text { diameter and bubble coverage } \\
\text { at the electrode surface }\end{array}$ & & & & & \\
\hline & $\begin{array}{l}\text { Zeeman energy, MHD } \\
\text { convection }\end{array}$ & $125 \mathrm{mT}$ & $\begin{array}{l}56 \mathrm{mV} \text { gain at } 20 \\
\mathrm{~mA} / \mathrm{cm}^{2}\end{array}$ & $\begin{array}{l}\text { urchin-like } \\
\mathrm{Co}_{3} \mathrm{O}_{4} \text { spheres } \\
\text { on the nickel } \\
\text { foam }\end{array}$ & $\begin{array}{l}\text { alkaline } \mathrm{pH} 14 \\
(1 \mathrm{M} \mathrm{KOH})\end{array}$ & [34] \\
\hline & Kelvin force & $150 \mathrm{mT}$ & $\begin{array}{l}5.8 \mathrm{~mA} / \mathrm{cm} \rightarrow 8.1 \\
\mathrm{~mA} / \mathrm{cm} \text { at }+0.2 \\
\mathrm{~V}_{\mathrm{RHE}} \text { for } \mathrm{ORR}\end{array}$ & $\begin{array}{l}\mathrm{Fe}-\mathrm{N}-\mathrm{C} / \mathrm{S} \\
\text { carbon gels }\end{array}$ & $\begin{array}{l}\mathrm{O}_{2} \text {-saturated } \\
0.02 \mathrm{M} \mathrm{PB} \\
\text { buffer with } \\
0.15 \mathrm{M} \mathrm{K}_{2} \mathrm{SO}_{4} \\
\text { of } \mathrm{pH} 5.5\end{array}$ & [30] \\
\hline & $\begin{array}{l}\text { Smaller adsorption energies } \\
\text { and bond creation energies }\end{array}$ & $\begin{array}{l}\text { magnetic } \\
\text { catalyst }\end{array}$ & $\begin{array}{l}-0.49 \mathrm{~V}_{\mathrm{RHE}} \text { at } 100 \\
\mathrm{~mA} / \mathrm{cm}^{2} \text { for } \mathrm{HER}\end{array}$ & $\mathrm{FeB} @ \mathrm{Fe}$ & $\begin{array}{c}\text { alkaline } \mathrm{pH} 14 \\
(1 \mathrm{M} \mathrm{KOH})\end{array}$ & [40] \\
\hline AMF & Hyperthermia & $\begin{array}{l}48 \mathrm{mT} \text { at } 300 \\
\mathrm{kHz} \text { during } \\
\text { experiment }\end{array}$ & $\begin{array}{l}18 \mathrm{~mA} / \mathrm{cm}^{2} \text { at } 1.60 \\
\mathrm{~V} \text { vs. RHE (iR- } \\
\text { compensated) } \\
\text { - } 250 \mathrm{mV} \text { gain for } \\
\text { the OER and } 150 \\
\mathrm{mV} \text { gain for the } \\
\text { HER at } 18 \\
\mathrm{~mA} / \mathrm{cm}^{2}\end{array}$ & $\mathrm{FeC} @ \mathrm{Ni}$ & $\begin{array}{l}\text { alkaline pH } 14 \\
\text { (1 M KOH) }\end{array}$ & [68] \\
\hline
\end{tabular}

\section{Acknowledgments}

This work was supported by the National Research Agency, in the frame of the HyWalHy project (ANR-1-CE05-0017). Some of the work presented herein has been performed 
within the framework of the Centre of Excellence of Multifunctional Architectured Materials “CEMAM" No. ANR-10-LABX-44-01.

\section{Author contributions}

JD and MC have conceived and designed the study; all authors have equally analyzed and interpreted the data. VG did draft the first version of the article, which has been criticallyrevised and finally-approved by all authors equally.

\section{Lexicon}

$\boldsymbol{B}$ : magnetic flux density vector, its modulus is in Tesla. We abusively call it magnetic field.

$\boldsymbol{H}$ : magnetic field vector, its modulus is in $\mathrm{A} / \mathrm{m}$

$B_{/ /}$: magnetic field applied parallel to the electrode surface

$B \perp$ : magnetic field applied perpendicular to the electrode surface

$M$ : magnetization in $\mathrm{A} / \mathrm{m}$

$\boldsymbol{F}_{\mathrm{L}}$ : Lorentz force density vector, its modulus is in $\mathrm{N} / \mathrm{m}^{3}$

$\boldsymbol{F}_{\mathrm{K}}$ : Kelvin force density vector, its modulus is in $\mathrm{N} / \mathrm{m}^{3}$

$J$ : current density vector, its modulus is in $\mathrm{A} / \mathrm{m}^{2}$

$\boldsymbol{E}$ : electric field vector, its modulus is in N/C

$v$ : species velocity vector, its modulus is in $\mathrm{m} / \mathrm{s}$

$\sigma:$ electric conductivity in $S / m$

$d$ : distance from the permanent magnet

$\boldsymbol{u}_{\boldsymbol{\theta}}$ : second coordinate in the polar coordinates, $\boldsymbol{u}_{\mathbf{r}}$ and $\boldsymbol{u}_{\mathbf{z}}$ being the first and third coordinates, respectively.

$\chi$ : dimensionless magnetic susceptibility,

$\chi_{\mathrm{m}}$ : molar magnetic susceptibility in $\mathrm{m}^{3} / \mathrm{mol}$ 
$c$ : concentration of the species in $\mathrm{mol} / \mathrm{m}^{3}$

$\mu_{0}$ : magnetic permeability in free space, in $\mathrm{kg} \cdot \mathrm{m} \cdot \mathrm{A}^{-2} \cdot \mathrm{s}^{-2}$

$\nabla:$ gradient operator

$\nabla \times$ : rotational operator

$f$ : frequency in $\mathrm{Hz}$ 


\section{References and recommended reading}

Papers of particular interest, published within the period of review, have been highlighted as:

* $\quad$ Paper of special interest.

** Paper of outstanding interest.

[1] R. Aogaki, K. Fueki, T. Mukaibo, Application of Magnetohydrodynamic Effect to the Analysis of Electrochemical Reactions 1. MHD Flow of an Electrolyte Solution in an Electrode-Cell with a short Rectangular Channel, (1975) 504-508. https://doi.org/https://doi.org/10.5796/kogyobutsurikagaku.43.504.

[2] T.Z. Fahidy, Hydroynamic Models in Magnetoelectrolysis, Electrochim. Acta. 18 (1973) 607-614. https://doi.org/https://doi.org/10.1016/0013-4686(73)85026-1.

[3] S. Mori, K. Satoh, A. Tanimoto, Electrolytic mass transfer around inclined cylinders in static magnetic fields, Electrochim. Acta. $39 \quad$ (1994) 2789-2794. https://doi.org/https://doi.org/10.1016/0013-4686(94)E0193-4.

[4] J. Lee, S.R. Ragsdale, X. Gao, H.S. White, Magnetic field control of the potential distribution and current at microdisk electrodes, J. Electroanal. Chem. 422 (1997) 169177. https://doi.org/https://doi.org/10.1016/S0022-0728(96)04878-4.

[5] A. Chiba, K. Kitamura, T. Ogawa, Magnetic Field Effects On The Electrodeposition Of Nickel From a High pH Watt's Bath, Surf. Coatings Technol. 27 (1986) 83-88. https://doi.org/https://doi.org/10.1016/0257-8972(86)90047-2.

[6] L.B. Wang, N.I. Wakayama, T. Okada, Numerical simulation of a new water management for PEM fuel cell using magnet particles deposited in the cathode side catalyst layer, Electrochem. Commun. $4 \quad$ (2002) 584-588. https://doi.org/doi.org/10.1016/S1388-2481(02)00383-1.

[7] L.B. Wang, N.I. Wakayama, T. Okada, Management of Water Transport in the Cathode 
of Proton Ex-change Membrane Fuel Cells Using Permanent Magnet Particles Deposited in the Cathode-side Catalyst Layer, ISIJ Int. 45 (2005) 1005-1013. https://doi.org/doi.org/10.1016/S1388-2481(02)00383-1.

[8] K. Kołodziejczyko, E. Miękoś, M. Zieliński, M. Jaksender, D. Szczukocki, K. Czarny, Influence of constant magnetic field on electrodeposition of metals, alloys, conductive polymers, and organic reactions, J. Solid State Electrochem. 22 (2018) 1629-1647. https://doi.org/doi.org/10.1007/s10008-017-3875-x.

[9] R. Naaman, Y. Paltiel, D.H. Waldeck, Chiral molecules and the electron spin, Nat. Rev. Chem. 3 (2019) 250-260. https://doi.org/10.1038/s41570-019-0087-1.

* This contribution explores spin effects for chiral molecules and describes methods to measure electron-spins.

[10] S. Mishra, M. Marzio, R. Giovanardi, F. Tassinari, Magnetoelectrochemistry and Asymmetric Electrochemical Reactions, Magnetochemistry. 6 (2020) 1-7. https://doi.org/10.3390/magnetochemistry6010001.

[11] L.M.A. Monzon, J.M.D. Coey, Magnetic fields in electrochemistry: The Lorentz force. A mini-review, Electrochem. Commun. $42 \quad$ (2014) 38-41. https://doi.org/10.1016/j.elecom.2014.02.006.

** This paper reviews the effects of the Lorentz force in electrochemistry.

[12] L.M.A. Monzon, J.M.D. Coey, Magnetic fields in electrochemistry: The Kelvin force . A mini-review, Electrochem. Commun. $42 \quad$ (2014) 42-45. https://doi.org/10.1016/j.elecom.2014.02.005.

** This paper reviews the effects of the Kelvin force in electrochemistry.

[13] I. Vincent, B. Choi, M. Nakoji, Pulsed current water splitting electrochemical cycle for hydrogen production, Int. J. Hydrog. Energy. 43 (2018) 10240-10248. https://doi.org/10.1016/j.ijhydene.2018.04.087. 
[14] T. Weier, J. Hüller, G. Gerbeth, F.P. Weiss, Lorentz force influence on momentum and mass transfer in natural convection copper electrolysis, Chem. Eng. Sci. 60 (2005) 293298. https://doi.org/10.1016/j.ces.2004.07.060.

[15] H. Liu, H. Xu, L. Pan, D. Zhong, Porous electrode improving energy efficiency under electrode-normal magnetic field in water electrolysis, Int. J. Hydrog. Energy. 44 (2019) 22780-22786. https://doi.org/10.1016/j.ijhydene.2019.07.024.

** In this paper, Liu et al. use magnetic effects (Lorentz force and MHD) to remove bubbles during water electrolysis, hence enhancing the reaction kinetics.

[16] L.M.A. Monzon, V. Nair, B. Reilly, J.M.D. Coey, Magnetically-Induced Flow during Electropolishing, J. Electrochem. Soc. $165 \quad$ (2018) 6-11. https://doi.org/10.1149/2.0581813jes.

* This paper explores how the MHD and Lorentz force enable to enhance mass-transfer during electropolishing; it opens the way to additional effects linked to the charged bubble|electrolyte interface.

[17] H. Liu, L. Pan, Q. Qin, P. Li, Experimental and numerical investigation of gas - liquid flow in water electrolysis under magnetic field, J. Electroanal. Chem. 832 (2019) 293302. https://doi.org/10.1016/j.jelechem.2018.11.020.

[18] K. Scott, Process intensification: An electrochemical perspective, Renew. Sustain. Energy Rev. 81 (2018) 1406-1426. https://doi.org/10.1016/j.rser.2017.05.189.

** The contribution reviews magnetic effects that can influence electrodeposition (MHD, Lorentz and Kelvin forces)

[19] E. Katz, O. Lioubashevski, I. Willner, Magnetic Field Effects on Bioelectrocatalytic Reactions of Surface-Confined Enzyme Systems : Enhanced Performance of Biofuel Cells, J. Am. Chem. Soc. 127 (2005) 3979-3988. https://doi.org/10.1021/ja044157t.

[20] G. Hinds, J.M.. Coey, M.E.G. Lyons, Influence of magnetic forces on electrochemical 
mass transport, Electrochem. Commun. 3 (2001) 215-218. https://doi.org/doi.org/10.1016/S1388-2481(01)00136-9.

[21] C. Udagawa, M. Ueno, H. Toshinari, M. Maeda, S. Maki, S. Morimoto, Y. Tanimoto, Magnetic Field Effects on Electroless Deposition of Lead Metal-Lorentz Force Effects, Bull. Chem. Soc. Jpn. 91 (2018) 165-172. https://doi.org/10.1246/bcsj.20170238.

[22] I. Mogi, R. Morimoto, R. Aogaki, K. Takahashi, Effects of Vertical Magnetohydrodynamic Flows on Chiral Surface Formation in Magnetoelectrolysis, Magnetochemistry. 4 (2018) 40. https://doi.org/10.3390/magnetochemistry4030040.

** This paper shows that micro-MHD vortices and vertical MHD flow is indispensable for the chiral surface formation and that the vertical MHD flow plays a significant role in symmetry breaking of micro-MHD vortices.

[23] A. Wang, Q. Deng, L. Deng, X. Guan, J. Luo, Eliminating Tip Dendrite Growth by Lorentz Force for Stable Lithium Metal Anodes, Adv. Funct. Mater. 29 (2019) 1-7. https://doi.org/10.1002/adfm.201902630.

[24] K. Nishikawa, T. Saito, H. Matsushima, M. Ueda, Holographic interferometric microscopy for measuring $\mathrm{Cu} 2+$ concentration profile during $\mathrm{Cu}$ electrodeposition in a magnetic field, Electrochim. Acta. $297 \quad$ (2019) 1104-1108. https://doi.org/10.1016/j.electacta.2018.12.025.

[25] L. Yang, C. Chen, J. Yuan, L. Gao, Z. Shang, Z. Liu, Effect of applied magnetic field on the electroplating and magnetic properties of amorphous FeNiPGd thin film, J. Magn. Magn. Mater. 495 (2020) 165872. https://doi.org/10.1016/j.jmmm.2019.165872.

[26] J.A. Koza, F. Karnbach, M. Uhlemann, J. Mccord, C. Mickel, A. Gebert, S. Baunack, L. Schultz, Electrocrystallisation of CoFe alloys under the influence of external homogeneous magnetic fields - Properties of deposited thin films, Electrochem. Acta. 55 (2010) 819-831. https://doi.org/10.1016/j.electacta.2009.08.069. 
[27] A. Franczak, A. Levesque, F. Bohr, J. Douglade, J. Chopart, Structural and morphological modifications of the Co-thin films caused by magnetic field and $\mathrm{pH}$ variation, Appl. Surf. Sci. $\quad 258 \quad$ (2012) 8683-8688. https://doi.org/10.1016/j.apsusc.2012.05.074.

[28] A. Kumar, P.C. Mondal, Chiral Magneto-Electrochemistry, Magnetochemistry. 4 (2018) 36. https://doi.org/10.3390/magnetochemistry4030036.

[29] J. Romero, H. Prima-garcia, M. Varela, S.G. Miralles, V. Oestreicher, G. Abellán, E. Coronado, Giant Enhancement in the Supercapacitance of NiFe - Graphene Nanocomposites Induced by a Magnetic Field, Adv. Mater. 31 (2019) 1-8. https://doi.org/10.1002/adma.201900189.

[30] W. Kiciński, J.P. Sęk, E. Matysiak-brynda, K. Miecznikowski, M. Donten, B. Budner, A.M. Nowicka, Environmental Enhancement of PGM-free oxygen reduction electrocatalyst performance for conventional and enzymatic fuel cells : The influence of an external magnetic field, Appl. Catal. B. $258 \quad$ (2019) 117955. https://doi.org/10.1016/j.apcatb.2019.117955.

[31] Z. Zeng, W. Zhang, Z. Ji, Z. Yin, J. Wei, Magnetically-enhanced electron transfer from immobilized galvinoxyl radicals, Electrochem. Commun. 99 (2019) 36-40. https://doi.org/10.1016/j.elecom.2018.12.012.

[32] I. Mogi, R. Morimoto, R. Aogaki, Surface chirality effects induced by magnetic fields, Curr. Opin. Electrochem. 7 (2018) 1-6. https://doi.org/10.1016/j.coelec.2017.09.029.

* This paper reviews effects linked to the chirality of spins.

[33] P. Zou, J. Li, Y. Zhang, C. Liang, C. Yang, H. Jin, Nano Energy Magnetic- field-induced rapid synthesis of defect-enriched Ni-Co nanowire membrane as highly efficient hydrogen evolution electrocatalyst, Nano Energy. $51 \quad$ (2018) 349-357. https://doi.org/10.1016/j.nanoen.2018.06.080. 
[34] Y. Li, L. Zhang, J. Peng, W. Zhang, K. Peng, Magnetic field enhancing electrocatalysis of Co3O4/NF for oxygen evolution reaction, J. Power Sources. 433 (2019) 226704. https://doi.org/10.1016/j.jpowsour.2019.226704.

[35] S. Mohan, G. Saravanan, A. Bund, Role of magnetic forces in pulse electrochemical deposition of $\mathrm{Ni}$ nanoAl2O3 composites, Electrochim. Acta. 64 (2012) 94-99. https://doi.org/10.1016/j.electacta.2011.12.123.

[36] H. Liu, Q. Hu, L. Pan, R. Wu, Y. Liu, D. Zhong, Electrode-normal magnetic field facilitating neighbouring electrochemical bubble release from hydrophobic islets, Electrochim. Acta. 306 (2019) 350-359. https://doi.org/10.1016/j.electacta.2019.03.140.

[37] H. Liu, D. Zhong, J. Han, L. Pan, Hydrogen bubble evolution from magnetized nickel wire electrode, Int. J. Hydrog. Energy. 44 (2019) 31724-31730. https://doi.org/10.1016/j.ijhydene.2019.10.063.

[38] M.S. Cho, Y.Y. Yun, J.D. Nam, Y. Son, Y. Lee, Effect of magnetic field on electrochemical polymerization of EDOT, Synth. Met. 158 (2008) 1043-1046. https://doi.org/10.1016/j.synthmet.2008.07.006.

[39] R. Karpowicz, J. Lewkowski, M. Morawska, The aza-Pudovik reaction accelerated in external constant magnetic field, Chem. Pap. Short Commun. 70 (2016) 1529-1532. https://doi.org/10.1515/chempap-2016-0087.

[40] Y. Li, H. Li, Y. Li, S. Peng, Y. Hang, Fe-B alloy coupled with Fe clusters as an efficient cocatalyst for photocatalytic hydrogen evolution, Chem. Eng. J. 344 (2018) 506-513. https://doi.org/10.1016/j.cej.2018.03.117.

[41] WM Haynes, Magnetic Susceptibility of the Elements and Inorganic Compounds, Handb. Chem. Phys. (1998) 130-135.

[42] K. Tschulik, C. Cierpka, A. Gebert, L. Schultz, J.K. Christian, In Situ Analysis of ThreeDimensional Electrolyte Convection Magnetic Gradient Fields, Anal. Chem. 83 (2011) 
3275-3281. https://doi.org/10.1021/ac102763m.

[43] L.M.A. Monzon, K. Rode, M. Venkatesan, J.M.D. Coey, Electrosynthesis of Iron, Cobalt, and Zinc Microcrystals and Magnetic Enhancement of the Oxygen Reduction Reaction, Chem. Mater. 24 (2012) 3878-3885. https://doi.org/10.1021/cm301766s.

[44] K. Ray, S.P. Ananthavel, D.H. Waldeck, R. Naaman, Asymmetric Scattering of Polarized Electrons by Organized Organic Films of Chiral Molecules, Science (80-. ). 283 (1999) 814-817. https://doi.org/10.1126/science.283.5403.814.

[45] C. Fontanesi, Spin-dependent electrochemistry: A novel paradigm, Curr. Opin. Electrochem. 7 (2019) 36-41. https://doi.org/10.1016/j.coelec.2017.09.028.

* This papers reviews spin-dependant electrochemistry

[46] P.C. Mondal, W. Mtangi, C. Fontanesi, Chiro-Spintronics: Spin-Dependent Electrochemistry and Water Splitting Using Chiral Molecular Films, Small Method. 2 (2018) 1700313. https://doi.org/10.1002/smtd.201700313.

** This paper reviews spin-dependant electrochemistry, in particular for water-splitting.

[47] Z. Zeng, J. Wei, Y. Liu, W. Zhang, T. Mabe, J. Wei, Y. Liu, W. Zhang, T. Mabe, Magnetoreception of Photoactivated Cryptochrome 1 in Electrochemistry and Electron $\begin{array}{lllll}\text { Transfer, } & \text { ACS } & \text { Omega. } & 3 & \text { (2018) }\end{array}$ https://doi.org/10.1021/acsomega.8b00645.

[48] M.N. Baibich, J.M. Broto, A. Fert, F. Nguyen Van Dau, F. Petroff, Giant Magnetoresistance of (001)Fe/(001) Cr Magnetic Superlattices, Phys. Rev. Lett. 61 (1988) 2472-2475. https://doi.org/https://doi.org/10.1103/PhysRevLett.61.2472.

[49] W. Mtangi, F. Tassinari, K. Vankayala, A.V. Jentzsch, B. Adelizzi, A.R.A. Palmans, C. Fontanesi, E.W. Meijer, R. Naaman, Control of Electrons' Spin Eliminates Hydrogen Peroxide Formation During Water Splitting, J. Am. Chem. Soc. 139 (2017) 2794-2798. https://doi.org/10.1021/jacs.6b12971. 
** In this paper, Mtangi et al. precise how spin-polarization enables to orient reactions pathways.

[50] W. Mtangi, V. Kiran, C. Fontanesi, R. Naaman, Role of the Electron Spin Polarization in Water Splitting, J. Phys. Chem Lett. 6 (2015) 4916-4922. https://doi.org/10.1021/acs.jpclett.5b02419.

[51] D. Qi, A. Kenaan, D. Cui, J. Song, Novel insights into the selection to electron's spin of

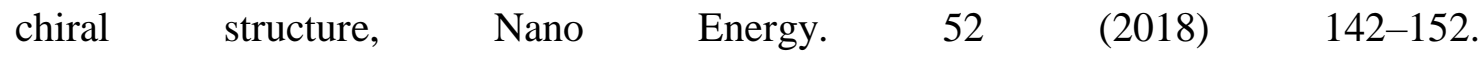
https://doi.org/10.1016/j.nanoen.2018.07.054.

[52] E. Torun, C.M. Fang, G.A. De Wijs, R.A. De Groot, Role of Magnetism in Catalysis: RuO2(110) Surface, J. Phys. Chem. C. 2 (2013) 6353-6357. https://doi.org/10.1021/jp4020367.

[53] F.A. Garcés-pineda, M. Blasco-ahicart, D. Nieto-castro, N. López, J.R. Galán-mascarós, Direct magnetic enhancement of electrocatalytic water oxidation in alkaline media, Nat. Energy. 4 (2019) 519-525. https://doi.org/10.1038/s41560-019-0404-4.

* This paper explore spin-polarization effects during oxygen evolution. The supporting information is of particular interest.

[54] J.S. Moodera, G. Mathon, Spin polarized tunneling in ferromagnetic junctions, J. Magn. Magn. Mater. 200 (1999) 248-273. https://doi.org/https://doi.org/10.1016/S03048853(99)00515-6.

[55] Z. Zeng, T. Zhang, Y. Liu, W. Zhang, Z. Yin, Z. Ji, J. Wei, Magnetic Field-Enhanced 4Electron Pathway for Well-Aligned Co3O4/Electrospun Carbon Nanofibers in the Oxygen Reduction Reaction, ChemSusChem. $11 \quad$ (2018) 580-588. https://doi.org/10.1002/cssc.201701947.

[56] R.P. Forslund, W.G. Hardin, X. Rong, A.M. Abakumov, C.T. Alexander, J.T. Mefford, H. Iyer, A.M. Kolpak, K.P. Johnston, K.J. Stevenson, Exceptional Electrocatalytic 
Oxygen Evolution Via Tunable Ruddlesden-Popper Oxides, Nat. Commun. 9 (2018) 3150. https://doi.org/10.1038/s41467-018-05600-y.

[57] H. Pan, M. Wang, Y. Shen, B. Hu, Large Magneto-Current Effect in the Electrochemical Detection of Oxalate in Aqueous Solution, J. Phys. Chem. C. 122 (2018) 19880-19885. https://doi.org/10.1021/acs.jpcc.8b04193.

[58] S. Bhattacharjee, S. Lee, Controlling Oxygen-Based Electrochemical Reactions through Spin Orientation, J. Phys. Chem. C. 122 (2018) 894-901. https://doi.org/10.1021/acs.jpcc.7b10147.

[59] C. Biz, M. Fianchini, J. Gracia, M. Fianchini, J. Gracia, Catalysis Meets Spintronics; Spin Potentials Associated with Open-Shell Orbital Configurations Enhance the Activity of Pt3Co Nanostructures for Oxygen Reduction: A Density Functional Theory Study, ACS Appl. Nano Mater. 3 (2020) 506-515. https://doi.org/10.1021/acsanm.9b02067.

[60] J. Gracia, M. Sl, G. Polavieja, Itinerant Spins and Bond Lengths in Oxide Electrocatalysts for Oxygen Evolution and Reduction Reactions, J. Phys. Chem. C. 123 (2019) 9967-9972. https://doi.org/10.1021/acs.jpcc.9b01635.

[61] J. Gracia, C. Biz, M. Fianchini, The trend of chemisorption of hydrogen and oxygen atoms on pure transition metals : Magnetism justifies unexpected behaviour of $\mathrm{Mn}$ and $\begin{array}{llllll}\text { Cr, } & \text { Mater. } & \text { Today } & \text { Commun. } & 23 & \text { (2020) }\end{array}$ https://doi.org/10.1016/j.mtcomm.2020.100894.

[62] J. Gracia, R. Sharpe, J. Munarriz, Principles determining the activity of magnetic oxides for electron transfer reactions, J. Catal. 361 (2018) 331-338. https://doi.org/10.1016/j.jcat.2018.03.012.

[63] A. Manabe, M. Kashiwase, T. Hashimoto, T. Hayashida, A. Kato, K. Hirao, I. Shimomura, I. Nagashima, Basic study of alkaline water electrolysis, Electrochim. Acta. 100 (2013) 249-256. https://doi.org/10.1016/j.electacta.2012.12.105. 
[64] G. Bullard, F. Tassinari, C. Ko, A.K. Mondal, R. Wang, S. Mishra, R. Naaman, M.J. Therien, Low-Resistance Molecular Wires Propagate Spin-Polarized Currents, J. Am. Chem. Soc. 141 (2019) 14707-14711. https://doi.org/10.1021/jacs.9b06142.

[65] S. Mishra, S. Pirbadian, A.K. Mondal, M.Y. El-naggar, Spin-Dependent Electron Transport through Bacterial Cell Surface Multiheme Electron Conduits, J. Am. Chem. Soc. 141 (2019) 19198-19202. https://doi.org/10.1021/jacs.9b09262.

[66] A. Kumar, E. Capua, C. Fontanesi, R. Carmieli, R. Naaman, Injection of Spin-Polarized Electrons into a AlGaN/GaN Device from an Electrochemical Cell: Evidence for an Extremely Long Spin Lifetime, ACS Nano. $12 \quad$ (2018) 3892-3897. https://doi.org/10.1021/acsnano.8b01347.

[67] F. Tassinari, K. Banerjee-ghosh, F. Parenti, V. Kiran, A. Mucci, R. Naaman, Enhanced Hydrogen Production with Chiral Conductive Polymer-Based Electrodes, J. Phys. Chem. C. 121 (2017) 15777-15783. https://doi.org/10.1021/acs.jpcc.7b04194.

[68] C. Niether, S. Faure, A. Bordet, J. Deseure, M. Chatenet, J. Carrey, B. Chaudret, A. Rouet, Improved water electrolysis using magnetic heating of $\mathrm{FeC}-\mathrm{Ni}$ core-shell nanoparticles, Nat. Energy. 3 (2018) 476-483. https://doi.org/10.1038/s41560-0180132-1.

** This paper explores hyperthermia and its interest to accelerate the kinetics of watersplitting reaction.

[69] G.F. Goya, L. Asín, M.R. Ibarra, Cell death induced by AC magnetic fields and magnetic nanoparticles : Current state and perspectives, Int. J. Hyperth. 29 (2013) 810-818. https://doi.org/10.3109/02656736.2013.838646.

[70] J. Carrey, B. Mehdaoui, M. Respaud, Simple models for dynamic hysteresis loop calculations of magnetic single-domain nanoparticles: Application to magnetic hyperthermia optimization, J. Appl. Phys. $109 \quad$ (2011) 083921. 
https://doi.org/10.1063/1.3551582.

[71] A.F.A.A. Melo, V.A.N. Carvalho, K.C. Pagnoncelli, F.N. Crespilho, Single microparticle applied in magnetic-switchable electrochemistry, Electrochem. Commun. 30 (2013) 79-82. https://doi.org/10.1016/j.elecom.2013.02.013.

[72] G. Bin, Z. Peng, J.I.N. Yongping, C. Shukang, Effects of alternating magnetic field on the corrosion rate and corrosion products of copper, Rare Met. 27 (2008) 324-328. https://doi.org/https://doi.org/10.1016/S1001-0521(08)60138-2.

[73] A. Tucs, V. Bojarevics, K. Pericleous, Magnetohydrodynamic stability of large scale liquid metal batteries, J. Fluid Mech. 852 (2018) 453-483. https://doi.org/10.1017/jfm.2018.482.

[74] J. Shu, S. Tang, Z. Feng, W. Li, X. Li, S. Zhang, Unconventional locomotion of liquid metal droplets driven by magnetic fields, Soft Matter. 14 (2018) 7113-7118. https://doi.org/10.1039/C8SM01281D.

[75] J. Shu, S. Tang, S. Zhao, Z. Feng, H. Chen, Rotation of Liquid Metal Droplets Solely Driven by the Action of Magnetic Fields, Appl. Sci. 9 (2019) 1421. https://doi.org/10.3390/app9071421.

[76] C. Warner, C.M. Mcdermid, A. Ahmadi, L. Markley, Impact of electrode design and voltage waveform on low-potential magnetohydrodynamic fluid actuation, Microfluid. Nanofluidics. 23 (2019) 1-8. https://doi.org/10.1007/s10404-019-2264-4.

[77] J.M.D. Coey, F.M.F. Rhen, P. Dunne, S. Mcmurry, The magnetic concentration gradient force - Is it real?, J. Solid State Electrochem. 11 (2007) 711-717. https://doi.org/10.1007/s10008-006-0254-4. 